\title{
The importance of atlantoaxial fixation after odontoidectomy
}

\author{
Peng-Yuan Chang, MD, 1,3 Yu-Shu Yen, MD, 1,3 Jau-Ching Wu, MD, PhD, 1,3 Hsuan-Kan Chang, MD, 1,3 \\ Li-Yu Fay, MD, 1,3,4 Tsung-Hsi Tu, MD, ${ }^{1,3,5}$ Ching-Lan Wu, MD, ${ }^{2,3}$ Wen-Cheng Huang, MD, PhD, , ${ }^{1,3}$ and \\ Henrich Cheng, MD, PhD ${ }^{1-3}$
}

\begin{abstract}
${ }^{1}$ Department of Neurosurgery, Neurological Institute, and ${ }^{2}$ Department of Radiology, Taipei Veterans General Hospital; ${ }^{3}$ School of Medicine and ${ }^{4}$ Institute of Pharmacology, National Yang-Ming University; and ${ }^{5}$ Molecular Medicine Program, Taiwan International Graduate Program, Academia Sinica, Taipei, Taiwan
\end{abstract}

OBJECTIVE Although anterior odontoidectomy has been widely accepted as a procedure for decompression of the craniovertebral junction (CVJ), postoperative biomechanical instability has not been well addressed. There is a paucity of data on the necessity for and choice of fixation.

METHODS The authors conducted a retrospective review of consecutively treated patients with basilar invagination who underwent anterior odontoidectomy and various types of posterior fixation. Posterior fixation included 1 of 3 kinds of constructs: occipitocervical (OC) fusion with atlantoaxial (AA) fixation, OC fusion without $A A$ fixation, or $A A$-only (without $\mathrm{OC}$ ) fixation. On the basis of the use or nonuse of AA fixation, these patients were assigned to either the AA group, in which the posterior fixation surgery involved both the atlas and axis simultaneously, regardless of whether the patient underwent OC fusion, or the non-AA group, in which the OC fusion construct spared the atlas, axis, or both. Clinical outcomes and neurological function were compared. Radiological results at each time point (i.e., before and after odontoidectomy and after fixation) were assessed by calculating the triangular area causing ventral indentation of the brainstem in the CVJ.

RESULTS Data obtained in 14 consecutively treated patients with basilar invagination were analyzed in this series; the mean follow-up time was 5.75 years. The mean age was 53.58 years; there were 7 males and 7 females. The AA and non-AA groups consisted of 7 patients each. The demographic data of both groups were similar. Overall, there was significant improvement in neurological function after the operation $(p=0.03)$, and there were no differences in the postoperative Nurick grades between the 2 groups $(p=1.00)$. According to radiological measurements, significant decompression of the ventral brainstem was achieved stepwise in both groups by anterior odontoidectomy and posterior fixation; the mean ventral triangular area improved from $3.00 \pm 0.86 \mathrm{~cm}^{2}$ to $2.08 \pm 0.51 \mathrm{~cm}^{2}$ to $1.68 \pm 0.59 \mathrm{~cm}^{2}$ (before and after odontoidectomy and after fixation, respectively; $p<0.05$ ). The decompression gained by odontoidectomy (i.e., reduction of the ventral triangular area) was similar in the AA and non-AA groups $\left(0.66 \pm 0.42 \mathrm{~cm}^{2}\right.$ vs $1.17 \pm 1.42 \mathrm{~cm}^{2}$, respectively; $p=0.38)$. However, the decompression achieved by posterior fixation was significantly greater in the AA group than in the non-AA group (0.64 $\pm 0.39 \mathrm{~cm}^{2}$ vs $0.17 \pm 0.16 \mathrm{~cm}^{2}$, respectively; $\left.p=0.01\right)$.

CONCLUSIONS Anterior odontoidectomy alone provides significant decompression at the CVJ. Adjuvant posterior fixation further enhances the extent of decompression after the odontoidectomy. Moreover, posterior fixation that involves AA fixation yields significantly more decompression of the ventral brainstem than OC fusion that spares AA fixation.

http://thejns.org/doi/abs/10.3171/2015.5.SPINE141249

KEY WORDS atlantoaxial fixation; odontoidectomy; occipitocervical fixation; craniovertebral junction; cervical

A NTERIOR odontoidectomy has been widely accepted as the surgical approach for decompression at the craniovertebral junction (CVJ). ${ }^{6-8,21,23,36,38,39,42-45}$ Several reports have demonstrated the clinical effectiveness of combined posterior fixation and odontoidectomy in the management of basilar invagination (BI). 2,3,5,9,10,14,20,23, ${ }^{29-32,34} \mathrm{~A}$ spectrum of anomalies of the CVJ, including os odontoideum, platybasia, clival hypoplasia, and atlantooccipital hypoplasia, can cause various degrees of ventral compression at the brainstem and malalignment of the

ABBREVIATIONS $\mathrm{AA}=$ atlantoaxial; $\mathrm{BI}=$ basilar invagination; $\mathrm{CVJ}=$ craniovertebral junction; $\mathrm{OC}=$ occipitocervical .

SUBMITTED December 13, 2014. ACCEPTED May 13, 2015.

INCLUDE WHEN CITING Published online October 16, 2015; DOI: 10.3171/2015.5.SPINE141249. 
CVJ. ${ }^{14,15,18,22,24,28-34,40}$ These deformities might require both anterior decompression and posterior fixation to achieve adequate correction. ${ }^{12,44-46}$ Despite the innovation of various routes for odontoidectomy (e.g., transnasal, transoral, transcervical, and combined), there is a paucity of data addressing biomechanical instability after odontoidectomy. The best timing and choices of and the necessity for occipitocervical (OC) or atlantoaxial (AA) fusion after odontoidectomy are still not clear.

In this study, we analyzed images of a series of patient preoperation, postodontoidectomy, and postfixation CT or MR images. To our knowledge, this is the first study aimed at evaluating the effectiveness of odontoidectomy and fixation.

\section{Methods}

In this retrospective study, we reviewed the clinical and radiological data obtained in a series of consecutively treated adult patients with BI who underwent anterior odontoidectomy and posterior fixation. The anterior odontoidectomies were achieved via the standard transoral or endoscopic transnasal approach. The posterior fixations were composed of an OC or AA fusion construct. The indication for surgery was progressive quadriparesis or other myelopathy symptoms caused by ventral compression at the CVJ.

\section{Perioperative Management and Operative Techniques}

Halo traction was routinely performed for every patient before the operation. The entire traction process was done in an intensive care unit. Fluoroscopy/lateral radiography was performed after traction for the evaluation of stability and alignment at the CVJ. In general, the traction force was initiated from a weight of $3 \mathrm{lbs}$ and increased gradually to a maximum of $12 \mathrm{lbs}$. Adjustment of the direction of traction was made to optimize alignment and reduce the displaced bony structures at the CVJ before the operation. If the reduction result from the halo traction was limited and the ventral compression was still prominent, as was the case in our series of patients, the treatment was carried on to the next step (i.e., 2-phased surgery).

The 2-phased surgical management involved anterior odontoidectomy and posterior fixation. The interval between these 2 approaches was approximately 3-7 days. For anterior odontoidectomy, the patient was placed supine after the induction of general anesthesia with either halo-ring traction or halo-vest immobilization. The odontoidectomy was achieved via the endoscopic transnasal or transoral approach with fluoroscopy and navigation guidance. The choice of surgical approach was tailored to each person's anatomical features seen on the preoperative MR images. The palatine line was adopted to differentiate the location of $\mathrm{BI}$ as high, intermediate, or low, ${ }^{13}$ and either the transnasal or transoral route was chosen. Detailed surgical procedures were described previously by us. ${ }^{44,45}$ After the first operation (i.e., anterior odontoidectomy), the patient was sent back to the intensive care unit. Subsequent radiographs and postoperative CT scans were obtained before the second operation to confirm the degree of decompression and to plan for the posterior fixation surgery.
Within 1 week, each patient was taken back to the operating room for the second-stage surgery (i.e., posterior fixation). Patients without evident deformity at the CVJ after odontoidectomy underwent AA fixation; for those with evident deformity, OC fixation was performed for further distraction and correction of the anomaly at the CVJ. After the fixation surgery, the halo vest was removed in the operating room and substituted with a Miami collar for postoperative support.

\section{Follow-Up Evaluations}

Standard anteroposterior, lateral, and open-mouth radiographs were obtained before the anterior odontoidectomy, between the odontoidectomy and posterior fixation, after the posterior fixation, and at the 3-, 6-, 12-, and 24-month follow-up visits. Multidetector thin-section coronal and sagittal CT reconstructions were also performed before the anterior odontoidectomy, between the odontoidectomy and posterior fixation, immediately after the posterior fixation, and 12 months after surgery. Furthermore, MRI was performed before the operation and 6 months afterward. Additional radiological follow-up was arranged at clinical visits annually. Clinical outcomes were assessed by using the Nurick grade. ${ }^{37}$ Preoperative and postoperative assessments were undertaken by the treating neurosurgeons at the clinical visits.

\section{Triangular Area at the Ventral CVJ}

In the sagittal plane images of each patient, a triangular area ventral to the brainstem was delineated (Fig. 1). The 3 points of this triangle were defined by the lowest point of the clivus, the posterior-inferior point of the C-2 vertebral body (axis), and the most dorsal indentation point in the ventral aspect of the brainstem (e.g., pannus formation [rheumatoid arthritis], os odontoideum, and the most cephalad-dorsal point [BI]).

The area of this triangle was measured and analyzed at each stage (i.e., before and after odontoidectomy and after
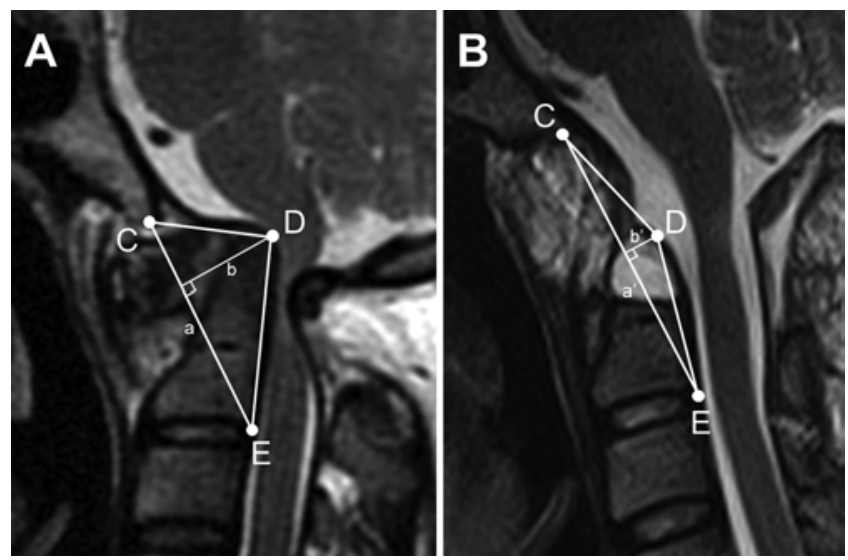

FIG. 1. Proposed assessment of ventral compression at the CVJ by using a simulated triangle. The 3 points of the triangle are the lowest point of the clivus $(C)$, the posterior-inferior point of the axial vertebral body $(E)$, and the most indenting point of the pathology $(D)$. The triangular area can be calculated as follows: $(a \times b) / 2$. After 2 operations (i.e., odontoidectomy and posterior fixation), the postoperative triangle area (B) was smaller than the preoperative triangular area (A). 
fixation), as illustrated in Fig. 1. Measurements were completed by using quantitative analyzing software (SmartIris, Taiwan Electronic Data Processing Co.).

\section{Statistical Analysis}

Independent t-tests and paired t-tests were used to analyze continuous variables with Excel (Microsoft) software. A p value of 0.05 was considered statistically significant. In the text and tables, mean values are presented \pm SD.

\section{Results}

\section{Demographics and Clinical Evaluations}

Between September 2004 and April 2013, 14 consecutively treated patients with BI who underwent anterior odontoidectomy with posterior fixation were enrolled for this analysis. The mean follow-up period for the series was $5.75 \pm 2.70$ years. There were 7 female and 7 male patients. Their mean age at the time of surgery was $53.38 \pm 14.28$ years. The etiologies of BI included rheumatoid arthritis $(n=6)$, chronic odontoid fractures $(n=4)$, os odontoideum $(\mathrm{n}=3)$, and seronegative spondyloarthropathy $(\mathrm{n}=1)$. Concomitant congenital anomalies included platybasia $(n=2)$ and atlantooccipital hypoplasia $(n=6)$. The mean preoperative Nurick grade was $4.07 \pm 1.20$, which improved to $3.00 \pm 1.30$ after the operations. The average improvement expressed by the Nurick grade was 1.07 (Table 1).

Among the 14 patients, 1 underwent transoral odontoidectomy, whereas the others underwent transnasal odontoidectomy for anterior decompression at the CVJ. Each of the 14 patients underwent subsequent posterior fixation, including OC (10) or AA (4) fixation. There was no definite deformity at the CVJ in the 4 patients whose fixation was confined to the $\mathrm{C} 1-2$ junction (Table 1, AAonly fixation without $\mathrm{OC}$ fusion). The other 10 patients underwent $\mathrm{OC}$ fixation surgery, among whom 3 had a fixation construct that involved both the axis and atlas (Table 1, OC fusion with AA fixation [OC+AA]); the axis, atlas, or both were omitted for the remaining 7 patients (Table 1 , OC fusion without AA fixation [OC-AA]) for various reasons.

The mean triangular area (calculation demonstrated in
Fig. 1) before surgery was $3.00 \pm 0.86 \mathrm{~cm}^{2}$. After anterior odontoidectomy, the average triangular area decreased to $2.08 \pm 0.51 \mathrm{~cm}^{2}(\mathrm{p}=0.002$, compared with the preoperative value) and decreased further to $1.68 \pm 0.59 \mathrm{~cm}^{2}$ after the stage- 2 posterior fixation surgery $(p=0.00007$, compared with the preoperative value, as illustrated in Fig. 2). The mean reduction in this triangular area (i.e., decompression gained by anterior odontoidectomy) was $0.92 \pm$ $1.04 \mathrm{~cm}^{2}$, and $0.40 \pm 1.04 \mathrm{~cm}^{2}$ was gained by posterior fixation surgery.

\section{AA Versus Non-AA Fixation}

Based on the segments involved in the posterior fixation surgeries, the 14 patients were assigned to 1 of 2 groups; the AA group consisted of 7 patients who underwent fixation that involved both the axis and atlas simultaneously, and the non-AA group consisted of the other 7 patients whose fixation surgery spared the axis, atlas, or both (Fig. 3 ). Thus, there was a 1-to-1 comparison of patients with fixation of the AA joint (i.e., the AA group) with those patients whose fixation excluded the AA joint (i.e., the non-AA group).

The demographic data between the AA and non-AA groups were similar (Table 2). The mean age of patients in the AA group was $55.91 \pm 17.57$ years, which is similar to that of the non-AA group $(51.25 \pm 10.96$ years; $\mathrm{p}=0.56)$. Clinical evaluations suggested that the mean preoperative Nurick grade was $4.14 \pm 0.90$ in the AA group, which was similar to that in the non-AA group $(4.00 \pm 1.53$; $\mathrm{p}=$ $0.83)$. After surgery, both groups demonstrated similar improvements in Nurick grades (AA vs non-AA group, 3.00 \pm 1.41 vs $3.00 \pm 1.29$, respectively; $p=1.00$ ); the mean improvement was approximately 1 grade in both groups $(1.14 \pm 1.07$ [AA group] and $1.00 \pm 1.15$ [non-AA group]; $\mathrm{p}=0.81$ ). It is worth noting that every patient experienced neurological improvement with or without a change in the Nurick grade.

Radiological assessments of the patients in both groups revealed significant decompression of the brainstem (a decrease of the triangular area at the ventral CVJ). In the AA group, the ventral triangular area improved from 2.8

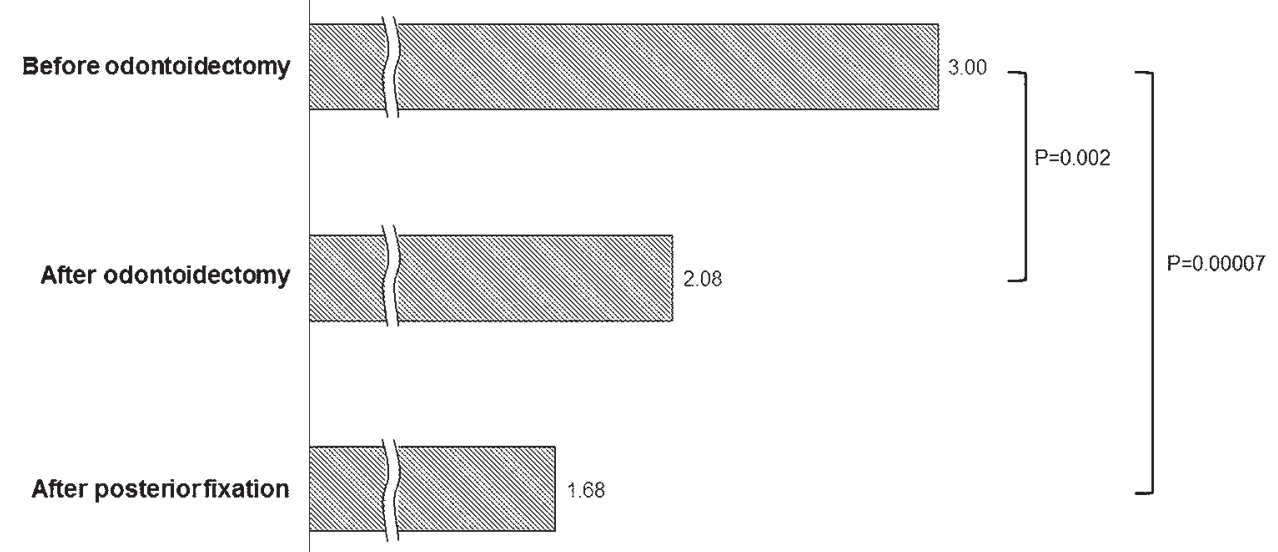

FIG. 2. Overall changes in the triangular area $\left(\right.$ in $\mathrm{cm}^{2}$ ) at different stages of management in this series. Odontoidectomy significantly reduced the ventral triangular area, and posterior fixation enhanced this reduction further. 


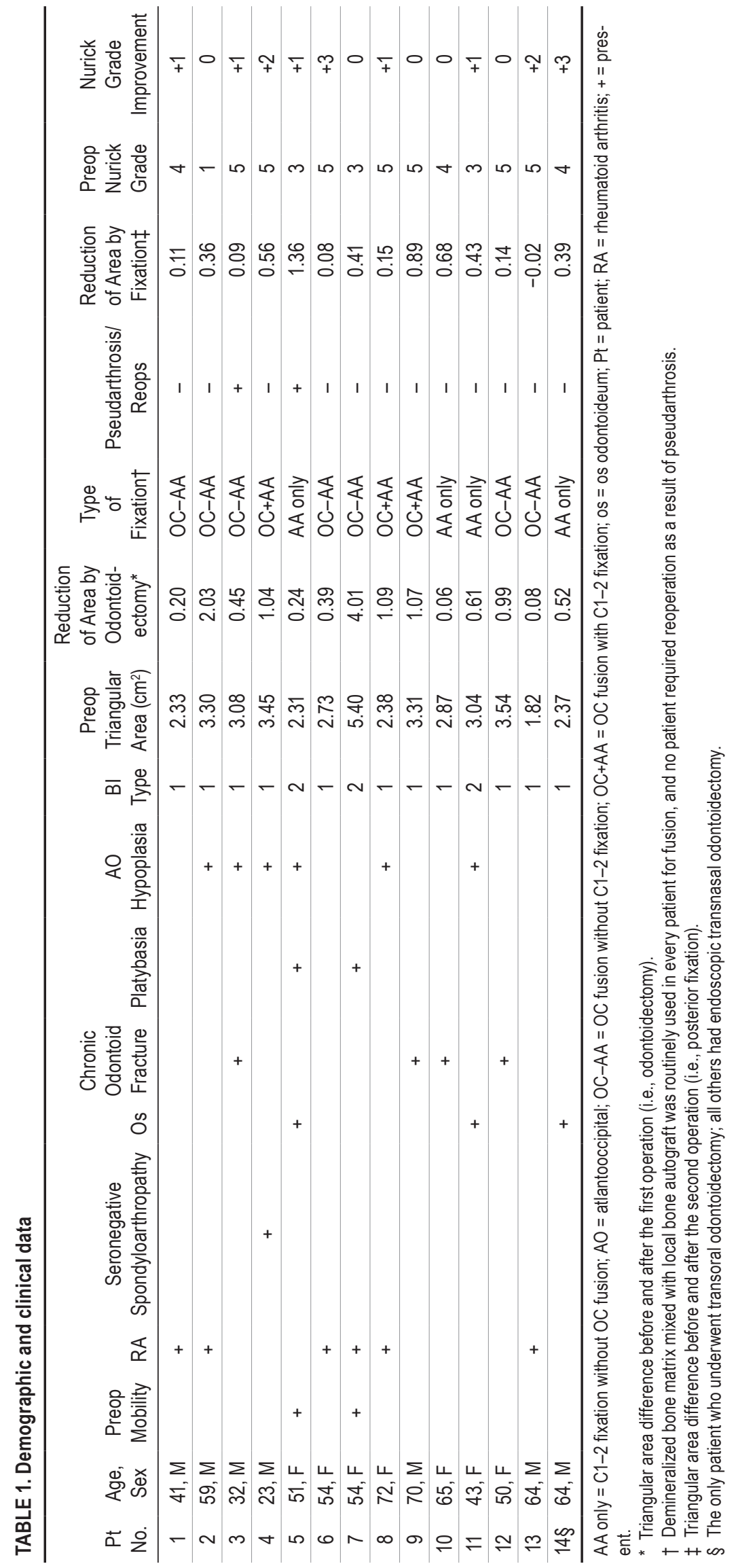



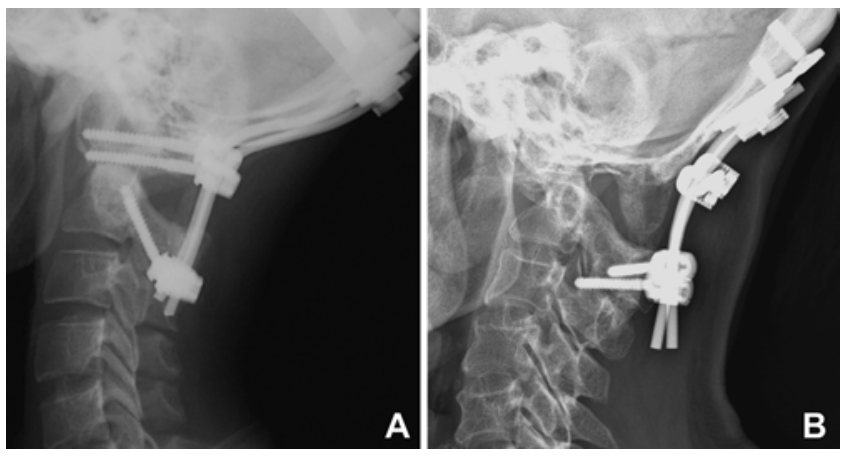

FIG. 3. A: Postoperative lateral radiograph of a 23-year-old man (from the AA group) who underwent posterior occipitoatlantoaxial fixation; this is the same patient shown in Fig. 1. B: Postoperative lateral radiograph of a 41-year-old man (from the non-AA group) who underwent posterior fixation in which hardware was placed in the occiput, axis, C-3 vertebra, and $\mathrm{C}-4$ vertebra.

to 2.2 to $1.5 \mathrm{~cm}^{2}$ (before and after odontoidectomy and after fixation, respectively; $\mathrm{p}<0.05$ ). In the non-AA group, the ventral triangular area improved from 3.2 to 2.0 to 1.8 $\mathrm{cm}^{2}$ (before and after odontoidectomy and after fixation, respectively; $p<0.05)$. The triangular areas at the ventral CVJ were similar at each stage of management (Table 3).

Both the AA and non-AA groups experienced stepwise decompression of the brainstem as a result of anterior odontoidectomy and then posterior fixation. The mean preoperative triangular areas were $2.82 \pm 0.48 \mathrm{~cm}^{2}$ in the AA group and $3.17 \pm 1.15 \mathrm{~cm}^{2}$ in the non-AA group. After anterior odontoidectomy, the triangular areas were $2.16 \pm$ 0.49 and $2.01 \pm 0.55 \mathrm{~cm}^{2}$, respectively. Both groups had significant reductions after the 2 staged operations compared with preoperative values $(\mathrm{p}=0.02$ [AA group] and 0.03 [non-AA group]). After the 2 staged operations, the areas were $1.52 \pm 0.51 \mathrm{~cm}^{2}$ in the AA group $(\mathrm{p}=0.003$ compared with the preoperative area) and $1.84 \pm 0.66 \mathrm{~cm}^{2}$ in the non-AA group ( $\mathrm{p}=0.02$ compared with the preoperative area).

Both anterior odontoidectomy and posterior fixation contributed to decompression of the brainstem (reduction of the triangular area at the ventral CVJ). The mean reductions of the triangular area gained by anterior odontoidec- tomy were similar in both groups $(0.66 \pm 0.42$ vs $1.17 \pm$ $1.42 \mathrm{~cm}^{2}$, respectively; $\mathrm{p}>0.05$ ). However, the AA group gained more decompression of the brainstem as a result of posterior fixation surgery than the non-AA group $(0.64 \pm$ 0.39 vs $0.17 \pm 0.16 \mathrm{~cm}^{2}$, respectively; $p=0.0127$ ). Therefore, patients with AA fixation gained more decompression than the patients of the non-AA group after anterior odontoidectomy (Table 3).

In this study, there were no postoperative hematomas, wound infections, or new-onset neurological deficits. There were no patients in this series who required a permanent feeding tube except 1 patient $(7.14 \%)$ with preexisting mechanical ventilator dependence. However, despite neurological improvement soon after the operation, 1 patient developed sepsis with multiple organ failure and died on postoperative Day 10.

\section{Subgroup Analysis}

The AA group was further broken down into 2 subgroups: the OC-with-AA group and the AA-only (without OC) group. The radiological measurements of all 3 groups, the OC-without-AA, OC-with-AA, and AA-only (without OC) groups, were compared (Table 3). The ventral triangular areas were similar before and after odontoidectomy and after fixation (Table 4).

Patients whose posterior fixation construct involved AA fixation (both the OC-with-AA and AA-only groups) experienced a statistically significant reduction in the triangular area ( $\mathrm{p}=0.047$ and 0.015 , respectively) when compared with the patients without AA fixation (the OC without AA group). There were no significant differences between the OC-with-AA and AA-only groups $(\mathrm{p}=0.61)$. Therefore, there was further reduction of the ventral triangular area at the $\mathrm{CVJ}$ as a result of AA fixation after odontoidectomy. This enhanced decompression was found in patients in the OC-with-AA and AA-only groups (Table 4).

\section{Discussion}

In this study, we focused on the clinical implication of AA involvement in posterior fixation surgery after odontoidectomy. We proposed a new measurement for assess-

TABLE 2. Demographic comparisons

\begin{tabular}{|c|c|c|c|}
\hline \multirow[b]{2}{*}{ Demographic } & \multicolumn{2}{|c|}{ Pt Group (mean \pm SD) } & \multirow[b]{2}{*}{$p$ Valuef } \\
\hline & $A A^{*}$ & Non-AA† & \\
\hline No. of pts & 7 & 7 & \\
\hline $\operatorname{Sex}(M / F)$ & $3: 4$ & $4: 3$ & \\
\hline Age (yrs) & $55.91 \pm 17.57$ & $51.25 \pm 10.96$ & 0.56 \\
\hline Radiographic follow-up (yrs) & $1.50 \pm 2.05$ & $2.96 \pm 3.28$ & 0.37 \\
\hline Clinical follow-up (yrs) & $5.21 \pm 1.96$ & $6.34 \pm 3.02$ & 0.45 \\
\hline Preop Nurick grade & $4.14 \pm 0.90$ & $4.00 \pm 1.53$ & 0.83 \\
\hline Postop Nurick grade & $3.00 \pm 1.41$ & $3.00 \pm 1.29$ & 1.00 \\
\hline Nurick grade improvement & $1.14 \pm 1.07$ & $1.00 \pm 1.15$ & 0.81 \\
\hline
\end{tabular}


TABLE 3. Radiographic outcomes

\begin{tabular}{|c|c|c|c|}
\hline \multirow[b]{2}{*}{ Outcome } & \multicolumn{2}{|c|}{ Pt Group (mean \pm SD) } & \multirow[b]{2}{*}{$p$ Value (if $<0.05$ ) } \\
\hline & $A A^{*}$ & Non-AA† & \\
\hline Preop area $\left(\mathrm{cm}^{2}\right)$ & $2.82 \pm 0.48$ & $3.17 \pm 1.15$ & \\
\hline Postodontoidectomy area $\left(\mathrm{cm}^{2}\right)$ & $2.16 \pm 0.49$ & $2.01 \pm 0.55$ & \\
\hline Postfixation area $\left(\mathrm{cm}^{2}\right)$ & $1.52 \pm 0.51$ & $1.84 \pm 0.66$ & \\
\hline First reduction $\left(\mathrm{cm}^{2}\right) \ddagger$ & $0.66 \pm 0.42$ & $1.17 \pm 1.42$ & \\
\hline Second reduction $\left(\mathrm{cm}^{2}\right) \S$ & $0.64 \pm 0.39$ & $0.17 \pm 0.16$ & 0.0127 \\
\hline
\end{tabular}

ing ventral compression at the CVJ. By using a simulated triangle (Fig. 1) defined by 3 points-the lowest point of the clivus, the posterior-inferior point of the C-2 vertebral body, and the most dorsal indentation point in the ventral aspect of the brainstem-the compression to the brainstem was quantified. This study retrospectively analyzed 14 consecutive patients with irreducible BI treated by anterior odontoidectomy and subsequent posterior fixation surgery. The patients were assigned to 1 of 2 groups: the AA group, in which the posterior fusion surgery included AA fixation, or the non-AA group, in which the OC fusion surgery skipped AA fixation. A significant decrease of the triangular area at the CVJ, which suggests successful decompression of the brainstem, was found in this series of patients after anterior odontoidectomy and after posterior fixation. The improvements in neurological function and clinical evaluation results also corroborate the effectiveness of the 2-staged operations in an average follow-up period of 5.75 years. Both the AA and non-AA groups experienced similar significant decompression of the brainstem as a result of odontoidectomy. However, significantly more decompression (further reduction of the triangular area at the ventral CVJ) was gained after posterior fixation by the AA group than by the non-AA group $\left(0.64\right.$ vs $0.17 \mathrm{~cm}^{2}$, respectively; $p=0.0127$ ). Therefore, this study demonstrated that adjuvant posterior fixation after odontoidectomy further enhances the extent of decompression, even after successful odontoidectomy. Furthermore, posterior fixation that involved AA fixation yielded significantly more decompression of the ventral brainstem than OC fusion that spared AA fixation. This is the first report to quantitatively suggest that AA fixation be included in posterior fixation surgery after anterior odontoidectomy.

The biomechanics and anomalies of the CVJ are of great complexity and have been addressed less commonly in the literature. These anomalies can be categorized as congenital or developmental/acquired (i.e., acquired through trauma, infection, or neoplasm). ${ }^{33}$ For the optimal treatment options, one should consider the etiology of the pathology, the segmental instability and reducibility, the mechanics of compression, and the direction of encroachment. ${ }^{31}$ Menezes ${ }^{31}$ proposed a treatment algorithm for craniovertebral abnormalities with a primary goal of relieving compression. For reducible lesions, the main purpose of treatment is to stabilize and maintain the proper neural structure. For irreducible lesions, decompression is required at the site at which the encroachment of neural tissue has occurred. The concept of management was straightforward and convincing based on the extensive clinical data published by Menezes et al. ${ }^{28-30,32,34,35,41}$ In our study, all the included patients had irreducible BI, in which case odontoidectomy was necessary, in addition to posterior fixation. The problem was determining which segments of the posterior fixation anchor would yield the most optimal outcome.

Currently, there are no guidelines for posterior fusion

TABLE 4. Radiographic outcomes (subdivision of the AA group in Table 3)

\begin{tabular}{|c|c|c|c|c|}
\hline Outcome & $O C w / 0 A^{*}$ & $O C w / A A^{*}$ & AA Only* & $p$ Value (if <0.05) \\
\hline No. of pts & 7 & 3 & 4 & \\
\hline Preop area $\left(\mathrm{cm}^{2}\right)$ & $3.17 \pm 1.15$ & $3.05 \pm 0.58$ & $2.65 \pm 0.37$ & \\
\hline Postodontoidectomy area $\left(\mathrm{cm}^{2}\right)$ & $2.01 \pm 0.55$ & $1.98 \pm 0.61$ & $2.29 \pm 0.43$ & \\
\hline Postfixation area $\left(\mathrm{cm}^{2}\right)$ & $1.84 \pm 0.66$ & $1.44 \pm 0.36$ & $1.57 \pm 0.65$ & \\
\hline First reduction $\left(\mathrm{cm}^{2}\right) \dagger$ & $1.17 \pm 1.42$ & $1.07 \pm 0.03$ & $0.36 \pm 0.25$ & \\
\hline Second reduction $\left(\mathrm{cm}^{2}\right) \ddagger$ & $0.17 \pm 0.16$ & $0.54 \pm 0.37$ & $0.71 \pm 0.44$ & $\S$ \\
\hline \multicolumn{5}{|c|}{ 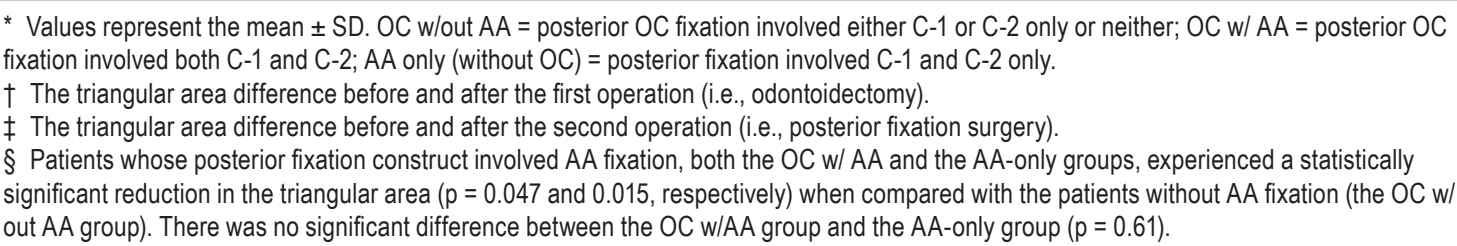 } \\
\hline
\end{tabular}


after odontoidectomy. In 2008, Ahmed et al. ${ }^{1}$ reported results of a study of a series of more than 750 pediatric OC fusions with good clinical outcomes. The patients were treated with OC fixation for severe reducible BI, unstable dystopic os odontoideum, unilateral C-1 assimilation, or traumatic OC dislocation or after transoral CVJ decompression. Conversely, Goel ${ }^{14}$ reviewed his institutional and personal 25-year experience of $\mathrm{BI}$ and proposed a new classification (Types A and B), in which the categorization was based on the relative alignment of the clivus, the axis, and atlas. In his classification, Type A BI indicated that there was a fixed AA dislocation and the tip of the odontoid process invaginated into the foramen magnum, whereas Type B meant that the odontoid process and clivus remained aligned despite the presence of BI. The classifications correlated with the treatment options. The author proposed a posterior fixation surgery for Type A $\mathrm{BI}$, which consisted of wide AA exposure, excision of the AA facet capsule, and distraction in addition to AA fixation with screws and plates..$^{15,17-19}$ For Type B BI, the treatment was foramen magnum decompression. In this theory, no anterior decompression was required, and the clinical outcomes were satisfying. However, perfectly reduced AA dislocation might not always be achievable in regular practice. It was generally agreed that irreducible BI would benefit from anterior decompression followed by posterior fixation. However, the successful clinical experience of Goel et al. ${ }^{14-20}$ suggests that the biomechanics of the AA complex was intriguingly beyond our understanding. Thus, we focused on the effectiveness of involving AA fixation in the posterior fixation and its synergic benefit after anterior odontoidectomy.

The optimal timing of, approach to, and instrumentation for OC fusion were still not clear. Reports have shown that the risk of nonunion obviously increases when the construct of AA fixation is extended to the OC fixation. ${ }^{11,26}$ Although arthrodesis at the CVJ is beneficial for the correction of deformity between the clivus and cervical spine, it inevitably limits the direction of gaze, oropharyngeal musculature, and head motion. ${ }^{4,25,27}$ The patient is usually placed in a prone position during the posterior OC fixation; thus, it is sometimes problematic determining the angle for fusion. An inadvertently aligned OC construct can cause postoperative dysphagia or dyspnea. In other words, OC fusion should be reserved for patients whose deformity in the CVJ requires fixation or in which instability exists, and a thorough preoperative plan is mandatory. However, in clinical practice, there is a lack of standard evaluation for segmental instability of the atlantooccipital joints.

Our study shows that posterior fixation after odontoidectomy provided indirect decompression to the brainstem, and this effect was more prominent in the patients with AA fixation than those who underwent $\mathrm{OC}$ fusion without AA fixation. These results suggest the importance of including AA fixation in the fusion construct simultaneously. Although it is reasonable to infer that involving AA fixation provides strong anchoring of the screws and better correction of the deformity that exists in the CVJ, additional studies are needed. For instance, this phenomenon could also be caused by the pooling of those suboptimal OC fixations. Fixation and correction of deformity limited to the AA complex is definitely more predictable than that performed at the OC complex. The proposed measurement of this series, using the triangular area, might assist in evaluating for and predicting the results of OC fixation. Furthermore, the biomechanics of the AA complex after odontoidectomy has been addressed even less commonly. The results from our series also indicated that AA fixation might not be avoidable. However, this theory requires additional investigation.

There were limitations in this current study. It was a nonrandomized retrospective study of a relatively small sample size. Study of a greater number of patients with $\mathrm{OC}$ and $\mathrm{AA}$ fixation is required to determine the actual outcomes of fixation after odontoidectomy. Although the AA and non-AA groups in our series were allocated by the surgeons, there was little difference in the demographic data between the 2 groups (Table 2). The results of this study actually merit the proposal that direct measurement of the degree of compression (triangular area in the ventral $\mathrm{CVJ}$ ) be done by calculating the triangular area differences in the preoperation, postodontoidectomy, and postfixation images (i.e., CT and MRI images). We also specifically analyzed the images obtained between the 2 staged operations to differentiate the effectiveness of anterior decompression and posterior fixation. Furthermore, the triangular area adopted in this current study may have merely measured the mass effect at the CVJ in the sagittal plane, and we might have overlooked rotational and coronal deformity. The measurement was also insufficient for depicting the alignment of the clivus and AA joint complex. We also neglected the causes of skipping AA fixation in the posterior fusion surgery. In some early cases in the series, AA fixation was avoided intentionally because of technical difficulties, anatomical variances, or surgeon preference. Nevertheless, this study provides quantification of the decompression after each stage of the operations.

\section{Conclusions}

Anterior odontoidectomy alone provides significant decompression at the CVJ. Adjuvant posterior fixation further enhances the extent of decompression after odontoidectomy. Moreover, posterior fixation that involves AA fixation yields significantly more decompression of the ventral brainstem than $\mathrm{OC}$ fusion that spares AA fixation. Although the clinical improvements in neurological function were similar in this study, AA fixation is advocated after anterior odontoidectomy to achieve better outcomes.

\section{References}

1. Ahmed R, Traynelis VC, Menezes AH: Fusions at the craniovertebral junction. Childs Nerv Syst 24:1209-1224, 2008

2. Anderson RC, Kan P, Gluf WM, Brockmeyer DL: Long-term maintenance of cervical alignment after occipitocervical and atlantoaxial screw fixation in young children. J Neurosurg 105 (1 Suppl):55-61, 2006

3. Baaj AA, Vrionis FD: Atlantoaxial stabilization utilizing atlas translaminar fixation. J Clin Neurosci 17:1578-1580, 2010

4. Bagley CA, Witham TF, Pindrik JA, Davis RF, Bydon A, Gokaslan ZL, et al: Assuring optimal physiologic craniocer- 
vical alignment and avoidance of swallowing-related complications after occipitocervical fusion by preoperative halo vest placement. J Spinal Disord Tech 22:170-176, 2009

5. Brockmeyer DL, Apfelbaum RI: A new occipitocervical fusion construct in pediatric patients with occipitocervical instability. Technical note. J Neurosurg 90 (2 Suppl):271-275, 1999

6. Cornelius JF, Kania R, Bostelmann R, Herman P, George B: Transnasal endoscopic odontoidectomy after occipito-cervical fusion during the same operative setting-technical note. Neurosurg Rev 34:115-121, 2011

7. Crockard HA: The transoral approach to the base of the brain and upper cervical cord. Ann R Coll Surg Engl 67:321-325, 1985

8. Crockard HA: Transoral surgery: some lessons learned. Br J Neurosurg 9:283-293, 1995

9. Crockard HA, Calder I, Ransford AO: One-stage transoral decompression and posterior fixation in rheumatoid atlantoaxial subluxation. J Bone Joint Surg Br 72:682-685, 1990

10. Crockard HA, Pozo JL, Ransford AO, Stevens JM, Kendall BE, Essigman WK: Transoral decompression and posterior fusion for rheumatoid atlanto-axial subluxation. J Bone Joint Surg Br 68:350-356, 1986

11. Deutsch H, Haid RW Jr, Rodts GE Jr, Mummaneni PV: Occipitocervical fixation: long-term results. Spine (Phila Pa 1976) 30:530-535, 2005

12. Dickman CA, Kalani MY: Resolution of cervical syringomyelia after transoral odontoidectomy and occipitocervical fusion in a patient with basilar invagination and Type I Chiari malformation. J Clin Neurosci 19:1726-1728, 2012

13. El-Sayed IH, Wu JC, Ames CP, Balamurali G, Mummaneni PV: Combined transnasal and transoral endoscopic approaches to the craniovertebral junction. J Craniovertebr Junction Spine 1:44-48, 2010

14. Goel A: Basilar invagination, Chiari malformation, syringomyelia: a review. Neurol India 57:235-246, 2009

15. Goel A: Is atlantoaxial instability the cause of Chiari malformation? Outcome analysis of 65 patients treated by atlantoaxial fixation. J Neurosurg Spine 22:116-127, 2015

16. Goel A: Occipitocervical fixation: is it necessary? J Neurosurg Spine 13:1-2, 2010

17. Goel A: Treatment of basilar invagination by atlantoaxial joint distraction and direct lateral mass fixation. J Neurosurg Spine 1:281-286, 2004

18. Goel A, Desai KI, Muzumdar DP: Atlantoaxial fixation using plate and screw method: a report of 160 treated patients Neurosurgery 51:1351-1357, 2002

19. Goel A, Shah A: Atlantoaxial facet locking: treatment by facet manipulation and fixation. Experience in 14 cases. $\mathbf{J}$ Neurosurg Spine 14:3-9, 2011

20. Goel A, Sharma P: Craniovertebral junction realignment for the treatment of basilar invagination with syringomyelia: preliminary report of 12 cases. Neurol Med Chir (Tokyo) 45:512-518, 2005

21. Hadley MN, Spetzler RF, Sonntag VK: The transoral approach to the superior cervical spine. A review of 53 cases of extradural cervicomedullary compression. J Neurosurg 71:16-23, 1989

22. Hwang SW, Gressot LV, Chern JJ, Relyea K, Jea A: Complications of occipital screw placement for occipitocervical fusion in children. J Neurosurg Pediatr 9:586-593, 2012

23. Hwang SW, Heilman CB, Riesenburger RI, Kryzanski J: C1$\mathrm{C} 2$ arthrodesis after transoral odontoidectomy and suboccipital craniectomy for ventral brain stem compression in Chiari I patients. Eur Spine J 17:1211-1217, 2008

24. Karam YR, Menezes AH, Traynelis VC: Posterolateral approaches to the craniovertebral junction. Neurosurgery 66 (3 Suppl):135-140, 2010

25. Lall R, Patel NJ, Resnick DK: A review of complications associated with craniocervical fusion surgery. Neurosurgery 67:1396-1402, 2010

26. Lu DC, Roeser AC, Mummaneni VP, Mummaneni PV: Nuances of occipitocervical fixation. Neurosurgery 66 (3 Suppl):141-146, 2010

27. Mazur MD, Sivakumar W, Riva-Cambrin J, Jones J, Brockmeyer DL: Avoiding early complications and reoperation during occipitocervical fusion in pediatric patients. J Neurosurg Pediatr 14:465-475, 2014

28. Menezes AH: Clival and craniovertebral junction chordomas. World Neurosurg 81:690-692, 2014

29. Menezes AH: Craniovertebral junction abnormalities with hindbrain herniation and syringomyelia: regression of syringomyelia after removal of ventral craniovertebral junction compression. J Neurosurg 116:301-309, 2012

30. Menezes AH: Craniovertebral junction anomalies: diagnosis and management. Semin Pediatr Neurol 4:209-223, 1997

31. Menezes AH: Craniovertebral junction database analysis: incidence, classification, presentation, and treatment algorithms. Childs Nerv Syst 24:1101-1108, 2008

32. Menezes AH: Craniovertebral junction neoplasms in the pediatric population. Childs Nerv Syst 24:1173-1186, 2008

33. Menezes AH: Editorial on "The craniocervical junction and its abnormalities". Childs Nerv Syst 24:1089-1090, 2008

34. Menezes AH, Sonntag VK, Wang MY: The management of craniovertebral junction disorders. Foreword. Neurosurgery 66 (3 Suppl):1, 2010

35. Menezes AH, Traynelis VC, Gantz BJ: Surgical approaches to the craniovertebral junction. Clin Neurosurg 41:187-203, 1994

36. Mummaneni PV, Haid RW: Transoral odontoidectomy. Neurosurgery 56:1045-1050, 2005

37. Nurick S: The pathogenesis of the spinal cord disorder associated with cervical spondylosis. Brain 95:87-100, 1972

38. Patel AJ, Boatey J, Muns J, Bollo RJ, Whitehead WE, Giannoni CM, et al: Endoscopic endonasal odontoidectomy in a child with chronic Type 3 atlantoaxial rotatory fixation: case report and literature review. Childs Nerv Syst 28:1971-1975, 2012

39. Ponce-Gómez JA, Ortega-Porcayo LA, Soriano-Barón HE, Sotomayor-González A, Arriada-Mendicoa N, GómezAmador JL, et al: Evolution from microscopic transoral to endoscopic endonasal odontoidectomy. Neurosurg Focus 37(4):E15, 2014

40. Savage JG, Fulkerson DH, Sen AN, Thomas JG, Jea A: Fixation with C-2 laminar screws in occipitocervical or C1-2 constructs in children 5 years of age or younger: a series of 18 patients. J Neurosurg Pediatr 14:87-93, 2014

41. Taggard DA, Menezes AH, Ryken TC: Instability of the craniovertebral junction and treatment outcomes in patients with Down's syndrome. Neurosurg Focus 6(6):e3, 1999

42. Tun K, Kaptanoglu E, Cemil B, Karahan ST, Esmer AF, Elhan A: A neurosurgical view of anatomical evaluation of anterior C1-C2 for safer transoral odontoidectomy. Eur Spine J 17:853-856, 2008

43. Wolinsky JP, Sciubba DM, Suk I, Gokaslan ZL: Endoscopic image-guided odontoidectomy for decompression of basilar invagination via a standard anterior cervical approach. Technical note. J Neurosurg Spine 6:184-191, 2007

44. Wu JC, Huang WC, Cheng H, Liang ML, Ho CY, Wong TT, et al: Endoscopic transnasal transclival odontoidectomy: a new approach to decompression: technical case report. Neurosurgery 63:ONSE92-ONSE94, 2008

45. Yen YS, Chang PY, Huang WC, Wu JC, Liang ML, Tu TH, et al: Endoscopic transnasal odontoidectomy without resection of nasal turbinates: clinical outcomes of 13 patients. J Neurosurg Spine 21:929-937, 2014

46. Zileli M, Cagli S: Combined anterior and posterior approach for managing basilar invagination associated with Type I 
Chiari malformation. J Spinal Disord Tech 15:284-289, 2002

\section{Disclosure}

The authors report no conflict of interest concerning the materials or methods used in this study or the findings specified in this paper.

\section{Author Contributions}

Conception and design: JC Wu, PY Chang. Acquisition of data: JC Wu, PY Chang. Analysis and interpretation of data: JC Wu, PY Chang, HK Chang. Drafting the article: JC Wu, PY Chang,
HK Chang, Tu. Critically revising the article: JC Wu, Yen, Huang. Reviewed submitted version of manuscript: JC Wu, CL $\mathrm{Wu}$, Cheng. Approved the final version of the manuscript on behalf of all authors: JC Wu. Statistical analysis: JC Wu, PY Chang, Fay, Tu, CL Wu, Huang. Administrative/technical/material support: JC Wu, Yen, HK Chang, Fay, Tu, CL Wu. Study supervision: JC Wu, Huang, Cheng.

\section{Correspondence}

Jau-Ching Wu, Department of Neurosurgery, Neurological Institute, Taipei Veterans General Hospital, Rm. 508, 17F, No. 201, Shih-Pai Rd., Section 2, Peitou, Taipei 11217, Taiwan. email: jauching@gmail.com. 